\title{
WHY CHOOSE TAIWAN FOR TERTIARY EDUCATION? THE CASE OF MALAYSIAN STUDENTS IN CHINESE INDEPENDENT SCHOOLS
}

\author{
Siah Poh Chua ${ }^{1 *}$, Tan Chee Seng ${ }^{1}$, Tan Swee $\mathrm{Mee}^{2}$, Lim Kar Loke ${ }^{2}$ \\ and Lew Wei Him ${ }^{1}$ \\ ${ }^{1}$ Department of Psychology and Counselling, Faculty of Art and Science, \\ Universiti Tunku Abdul Rahman, Jalan Universiti Bandar Barat, \\ 31900 Kampar, Perak, Malaysia \\ ${ }^{2}$ Department of Languages and Linguistics, Faculty of Art and Social Sciences, \\ Universiti Tunku Abdul Rahman, Jalan Universiti Bandar Barat, \\ 31900 Kampar, Perak, Malaysia \\ *Corresponding author: siahpc@utar.edu.my
}

Publication date: 23 December 2020

To cite this article: Siah, P. C., Tan, C. S., Tan, S. M., Lim, K. L., \& Lew, W. H. (2020). Why choose Taiwan for tertiary education? The case of Malaysian students in Chinese independent schools. Asia Pacific Journal of Educators and Education, 35(2), 89-108. https://doi.org/10.21315/apjee2020.35.2.6

To link to this article: https://doi.org/10.21315/apjee2020.35.2.6

\begin{abstract}
Before Malaysian government liberalising its private tertiary education in the 1996 Education Act, Taiwan was one of the popular choices for students from Chinese Independent Schools (CIS) to further their tertiary education. However, the number of CIS students choosing Taiwan as the destination of their tertiary education keeps hiking up substantially despite more choices of higher education provided locally after the liberalisation. In light of this, this study aims to explore factors affecting country choice of Malaysian students from CIS in the meantime while they were to further their tertiary education. A mixed-method design was employed to investigate factors shaping this peculiar phenomenon. The researchers identified eight push-pull factors from the data coding of a focus group discussion in the first phase of the study. Based on the results, a questionnaire was crafted in the second phase of the study. Then, by engaging a purposive sampling, 869 Senior Three CIS students were recruited from several CIS in different states of Malaysia to participate in the survey at the second phase of the study. The findings revealed the importance of demographic factors administering CIS students in choosing Taiwan as a popular destination of pursuing tertiary education. In addition, the use of Chinese language as the medium of instruction in teaching and financial consideration were the pull factors contributing to the interpretation of the choice made by this group
\end{abstract}


of participants. Furthermore, students' perspective of choosing future career path and their concern of family also determine their choice of higher education. Overall, the study highlighted the importance to include demographic factors in the push-pull model. It further provides factual information for the stakeholders or policy makers to incorporate more effective strategies in recruiting CIS students.

Keywords: Chinese independent schools, country choice, Malaysia, Taiwan, tertiary education

\section{INTRODUCTION}

After the liberalisation of private tertiary education in the $90 \mathrm{~s}$, more choices are provided for Malaysian students to continue their tertiary education locally rather than going abroad. The scenario is especially relevant for students who study in Chinese Independent Schools (CIS). This group of students usually study abroad as the certificates they obtained are not recognised by the Malaysian government with the reasons that CIS is in a different school system run by a set of unique syllabus relatively against the national sovereignty in terms of curriculum and education philosophy (The Sun Daily, 2016). However, the liberalisation of private tertiary education has lifted the stiff limitation of choices in higher education as CIS students are consequently allowed to enroll themselves to local private universities with the Unified Examination Certificate (UEC) they obtained under this special school system. Nevertheless, it is interesting to know that the number of CIS students continuing their tertiary education in Taiwan remains increasing after the liberalisation of private tertiary education in Malaysia. By using a push and pull model as the framework, this study aims to find out the push and pull factors that make CIS students choose Taiwan instead of Malaysia as a destination to continue their tertiary education. The findings of the present study will fill in the knowledge gap on choices of tertiary education among CIS students. To the researchers' knowledge, very few empirical studies have been conducted in exploring the issue of tertiary education choice among CIS students. In addition, the findings would also provide factual information to the policymakers of the institutions for both countries, Malaysia and Taiwan.

\section{LITERATURE REVIEW}

Higher education is usually under the control of a government because most of its financial expenses are funded by the government. However, the market-type mechanisms have been introduced to the higher education system in recent years (Jongbloed, 2003). Due to the beliefs that the higher education choice among 
students is similar to consumers' satisfaction of purchasing products or services. The momentum of market forces in the higher education system would eventually improve the quality of higher education (Baldwin \& James, 2000). Higher education systems, especially those in the major English-speaking countries such as Australia, Canada, the U.K. and the U.S., were therefore required to develop business models to enlarge their markets (Binsardi \& Ekwulugo, 2003; The Secretary of State for Education and Skills, 2003).

The enrollment of international students is a valuable economic resource for many developed countries. According to ICEF Monitor (2015), more than 5 million students studied outside of their home countries, and most of them are from China and India. Among OECD countries, about 56\% of international students are from Asia, and more than $40 \%$ international students choose to study in Englishspeaking countries, such as Australia, Canada, the U.K. and the U.S. (Organisation for Economic Co-operation and Development [OECD], 2019). Therefore, it is not surprising that most studies relevant to the country choice of tertiary education are conducted among international students in Western countries (Ahmad \& Shah, 2018).

Based on these past studies, different push and pull factors have significantly affected international students choosing countries to continue their tertiary education (Maringe \& Carter, 2007). The push factors causing school leavers to prefer studying overseas instead of their home countries include the lack of local higher education institutions, loss of confidence to a better future, lack of career opportunities, poor economic standards after graduation, and unstable political and social situations (Bhorat et al., 2002; Dzvimbo, 2003; Mazzarol \& Norman Soutar, 1999). Some pull factors attracting students to choose a specific country have been identified. These factors include the country image perceived by the students, high-quality education, opportunity to develop excellent English language skills, the opting experience of living in a multicultural and diverse city, availability to gain part time jobs while studying, and opportunities of permanent residency (MacGregor, 2014).

Singapore, Malaysia and Japan have become new competitors to attract the enrolment of international students in the recent decades. However, the findings that conducted in Western countries may not be able to apply to international students who choose to study in Asia (Ahmad, Buchanan, \& Ahmad, 2016). Jon, Lee and Byun (2014) surveyed 425 international students in a private university in Seoul. According to the findings in this survey, the main factors that international students choose to study in Korea include the learning of Korean language and culture, scholarship opportunity and better future job opportunity. 
Furthermore, international students from Western countries are more enchanted by the experience of Korean culture, while Asian students more to the financial and practical aspects, such as visa application, near to home country, living cost and safety concerns.

Lee (2017) also used a mix-method design to examine the pull and push factors affecting Chinese students studying in Korea. The results show that the main push factors are stiff competition enrolling to the universities in their home countries, job market condition and the quality of Chinese higher education, while the main pull factors are the selectivity of the institutions and the recommendation proposed from their parents and friends.

Ahmad and Shah (2018) conducted a survey of 134 international students at two universities in China. Over $50 \%$ of the respondents are from South Asia, Africa and the Middle east. Their findings show that academic quality and international recognition, economic and social factors are the main pull factors. Interestingly, friends and family factors are the least important factors. Lee (2014) also surveyed 72 international students from three private universities in Taiwan. The main three pull factors surveyed are the friendly and supportive learning environment, quality of education, recognition of qualifications and cost of studying for a degree.

Kamal et al. (2016) surveyed pre-university students in Malaysia and China. They found that the program mode, total cost and country of creativity and design are most important pull factors for them to plan to study abroad. However, the total of cost for studying a degree is the most prominent factor for Malaysian students but not for Chinese students. On the contrary, having better future job prospects is the most important factor for Chinese students compared to their Malaysian counterparts.

Padlee, Kamaruddin and Baharun (2010) surveyed 656 international students who study in six private universities in Malaysia, and they conclude that entry qualification, English as the medium of teaching, academic staff, facilities, visa application and religion are the most important pull factors. Nevertheless, international students from Africa and the Middle East perceived that the quality of learning environment is the most important pull factor whereas international students from Southeast Asia perceived socialising activities and cost of education as most important pull factors.

Overall, these studies indicated the complexity of the pull and push factors among international students with different demographic backgrounds and the countries they choose to continue their tertiary education. As suggested by Hemsley-Brown 
and Oplatka (2014), after reviewing 75 publications, they claim that it is important to consider demographic differences in university choice, as the student market of higher education is more like a segmented market than a single one. In other words, it is impossible to create a list of push and pull factors that suit describing all international students.

\section{Choice of Tertiary Education among Chinese Independent School Students}

The suggestions given by Hemsley-Brown and Oplatka (2014) can also be applied to CIS students in Malaysia, as the push and pull factors among CIS students to study abroad may also be different from other international students with diverse backgrounds. Malaysian Chinese comprised about a quarter of the total population of Malaysia (Department of Statistics Malaysia, 2018). Most Malaysian Chinese believe that Chinese education is the conduit to pass down the wealth of cultural heritage to the young (Chin, 2001). Some parents continue sending children to CIS for secondary education as these parents see that their children will have better chances to learn Chinese language and Chinese cultural values (Siah et al., 2015; 2018). In general, CIS are privately funded by the Malaysian Chinese community and the academic qualification or certification obtained (in this case, UEC) is not recognised by the Malaysian government (Yeoh, 2013). The situation is rather peculiar as UEC is widely accepted by universities from many countries despite the truth that it is rejected by its home country (Ho, 2015). As a result, many CIS students were segregated by the gate of public local universities but with no choice to pursue their tertiary education overseas.

A new milestone was stabbed in 1996 when the government liberalised Malaysian tertiary education through the 1996 Education Act. The liberation has opened up a new channel for Malaysian in Chinese and Indian origins to have more chances furthering their studies locally in private universities run by the corporate sector (Brown, 2007).

According to Malaysian Qualification Agency (2020), there are 83 private institutions located in different states in Malaysia, including the University of Nottingham Malaysia Campus, Heriot-Watt University Malaysia, Help University, Sunway University and so forth. With relatively lower tuition fees, CIS students could also opt for universities funded by the Chinese community like Universiti Tunku Abdul Rahman, Tunku Abdul Rahman University College, New Era University College and Southern University College.

With this emerging trend, CIS students appear to have many choices in continuing their tertiary education locally. Surprisingly, the number of CIS students opting 
Taiwan as their choice of tertiary education keeps growing in a positive trend even though these students are given more choices in hands. It was reported that among all CIS students who continue their tertiary education, $59.78 \%$ choose to study in Malaysia. Noticeably, Taiwan is the oversea country most chosen by CIS students with the percentage of $42.41 \%$ in 2017 (United Chinese School Committees' Association of Malaysia, 2017).

\section{Aim of the Study}

As mentioned by Hemsley-Brown and Oplatka (2014), it is important to consider demographic differences in surveying university choice. Thus, this study aims to identify the push-pull factors found among CIS students choosing Taiwan. Subsequently, it is hoped to outline the association between demographic factors with university choice in addition to linking the push and pull factors to the choice of studying in Taiwan.

\section{METHODOLOGY}

We employed an exploratory mixed method design in exploring the issue, hoping that the significant findings would shed lights on the field study. Since there is no appropriate measurement which could suit the current sample who lives in a multi-cultural context, a focus group discussion was conducted in the first phase for collecting data. Thematic analysis was used to identify factors that are relevant to the country choice of tertiary education. A questionnaire was designed in the second phase based on the data coded from the first phase of study. Factor analysis was used to examine the factor structure in designing the questionnaire, and regression analysis was used to explore effects of these factors on their choice of studying in Taiwan.

This study aims to:

1. Identify push and pull factors relevant to the country choice of tertiary education (Phase One).

2. Examine the structure of push and pull factors in the designed questionnaire (Phase Two).

3. To examine demographic factors associated with the choice of Taiwan for tertiary education (Phase Two).

4. Examine push and pull factors corelated to the choice of Taiwan for tertiary education (Phase Two). 


\section{PHASE ONE STUDY}

\section{Participants}

To identify factors relevant to the country choice of tertiary education among students of CIS, a focus group discussion was conducted in a CIS following the procedure suggested by Wong (2008). Ten Senior Three CIS students (Eight females and two males) were recruited by the teacher who is in charge of students' self-development in the counselling department of the school. The students were selected as they came to the counselling department seeking information about local or overseas tertiary education and were easily contacted by the counselling teacher. According to Krueger and Casey (2014), the ideal sample size of a focus group for any non-commercial topics is in the range of five to eight participants, and a larger sample size of eight is preferable when the study is designed to pilottest materials or ideas. Since it is the pilot-test for the development of a new inventory, a sample size of 10 is of saturation as no new information is being collected (McLafferty, 2004).

\section{Procedure}

During the group discussion, students were prompted to share their reasons of choosing a country to study further. The discussion was conducted in a meeting room. A researcher played the role as a facilitator asking questions, such as "Where do you want to continue your tertiary education?", "Why do you choose this country to continue your tertiary education?" and "Why do you choose this country but not any other else?" Participants were encouraged to discuss and exchange their ideas with one another during the discussion. The discussion was recorded in a MP3 recorder. Data collected was transcribed and coded afterwards.

\section{Data Analysis}

Following the procedure of thematic analysis suggested by Braun and Clarke (2006), we sorted and classified the data into various codes. Then we re-examined the codes and sorted them into potential themes. After that, we reviewed the themes for a couple of times, and combined and named similar themes into respective categories. 


\section{Results}

Eight themes affecting students' country choice of pursuing higher education were identified. The pull factors included the quality of higher education (facilities of the university are better and more advance than local university), medium of instruction in teaching (the language of instruction is Chinese, easier to adapt and fewer problems in learning), accessibility of information about the university (usually through the education fair and talks organised by the school), country image (Taiwanese are more polite and friendly), future job prospects (the country is developed better than Malaysia, so there will be more job opportunities than that in Malaysia), and family opinions (my brother is also studying there, so I chose to study in Taiwan). The push factors included financial consideration (the tuition fees of local private universities are high) and a better chance of self-development (we can go to other countries to learn their cultures).

\section{PHASE TWO STUDY}

\section{Participants}

The researchers recruited 869 Senior Three (equivalent to Form 6 in public secondary schools) students from eight CIS in the southern $(n=315)$, central $(n=315)$, northern $(n=166)$ and eastern $(n=73)$ regions of West Malaysia. About half of them were males (47\%). Their mean of age was $18.15(\mathrm{SD}=0.45)$. Over $80 \%$ of their parents obtained at least a secondary level of education or above $(83.9 \%$ for fathers and $85.3 \%$ for mothers).

\section{Procedure}

Based on the eight themes identified in the first study, a total of 40 items ( 5 items per factor) were then generated through the brainstorming among research team members (see the questionnaire). Moreover, one of the authors who has more than 10 years' experience of working with high school students scrutinised the items to ensure they are appropriate for high school students. After getting approval for ethical clearance from the Scientific and Ethical Committee of the university, we contacted 36 school principals in West Malaysia through emailing them to obtain permission conducting the survey in respective CIS. Their contact addresses were collected from Dong Zong, an organisation formed by the Association of Chinese School Management Boards or the Association of Chinese School Management Boards and Teachers from each state of the country. 
Eight school principals permitted us to conduct the survey in their schools. We posted questionnaire sets to the teachers in charge for the distribution and collection of questionnaires. On the other hand, some surveys were administered by one of our researchers on the arranged date and time suggested by the schools. On the cover page of the questionnaire, all students were briefed with the aims of the study, the confidentiality of the data they provided, and their right not to participate. It took about 15 minutes for participants to complete the questionnaire. A token of appreciation was given to each of the participants. One thousand and two hundred questionnaires were distributed, and 869 valid questionnaires were collected (response rate $=72.42 \%$ ). All of the collected data was then keyed in and analysed by using statistical software SPSS. A brief report was sent to the contact teachers of these schools for their reference.

\section{Questionnaire}

Based on the results of previously mentioned focus-group study, we worked out a questionnaire which contains two sections: (a) demographic information and (b) measurement of factors relevant to country choice, (c) the countries they intend to continue their tertiary education.

\section{Demographic information}

Participants were required to fill in information about themselves, such as age, gender, parents' highest level of education, number of family members who had received tertiary education.

\section{Factors affecting country choice}

Parallel with the eight factors identified in the focus group discussion in the first phase study, we brainstormed and generated relevant questions for the making of questionnaire. Five items were selected for each factor, contributing to a total of 40 items in the questionnaire. Participants were asked to fill in 5-point scale $(1=$ strongly disagree, $5=$ strongly agree $)$ to indicate the extent that they agreed with items describing the reasons of their country choice in the country they preferred. In other words, the higher the score, the more agreeable the participants made in the selected items. The samples items for each factor are education quality (Better quality of education in that country), the medium of instruction (Chinese as the medium of teaching in class), information about universities (More accessible to the information about tertiary education of that country from the current school), financial consideration (Lower tuition fees), a chance for 
self-development (Able to enhance the competency of self-management), future job consideration (Able to get a job in that country after graduation), family consideration (Family members are/have been studying there) and country image (People there are more friendly).

\section{Countries choice}

Participants need to tick a box to indicate the country they intend to continue their tertiary education, which includes Taiwan, Malaysia, China, Singapore, Australia, the U.K. and others.

\section{RESULTS}

\section{Factor Structure of the Survey Questions of Country Choice}

We used exploratory factor analysis (EFA) to explore the factor structure of the 40 items in the questionnaire. Principal Axis Factoring and Promax with Kaiser Normalisation rotation methods were adopted. A significant result was found in Bartlett's Test of Sphericity, $\chi^{2}(780, N=869)=17394.13, p<0.001$, and the KMO was 0.91 . Eight factors were extracted by using the Kaiser rule (i.e., eigenvalue $>1$ ), which explained $62 \%$ of the total variance. However, five items were deleted due to low factor loading $(<0.40)$ or cross-loading, which included the items "have the course that I would like to study" and "multiple national cultures". We conducted another EFA on the 35 items: Bartlett's Test of Sphericity, $\chi^{2}(595, N=869)=15387.21, p<0.001$, and the KMO was 0.91 . Similarly, eight factors were extracted and explained $65.05 \%$ of the total variance (see Table 1). Specifically, nine items were loaded on education quality, while medium of instruction consisted of four items. Information about universities, Financial Consideration and Chance for Self-development were accounted for five items respectively, whereas three items were loaded on future job consideration. Finally, both family consideration and country image comprised of two items. The overall reliability of the 35 items was 0.85 . 
Table 1. Factor loading of country choice survey

\begin{tabular}{|c|c|c|c|c|c|c|c|c|}
\hline \multirow{2}{*}{ Item } & \multicolumn{8}{|c|}{ Factor } \\
\hline & Quality & Medium & Information & Finance & Development & Job & Family & Country \\
\hline 1 & 0.84 & 0.05 & -0.03 & -0.04 & -0.01 & 0.01 & 0.03 & -0.10 \\
\hline 2 & 0.64 & 0.13 & 0.01 & 0.09 & -0.09 & -0.07 & -0.05 & 0.09 \\
\hline 3 & 0.79 & 0.02 & 0.09 & 0.03 & -0.06 & 0.09 & 0.03 & -0.17 \\
\hline 4 & 0.80 & 0.05 & 0.05 & 0.02 & -0.10 & 0.11 & 0.02 & -0.07 \\
\hline 5 & 0.86 & -0.09 & -0.02 & 0.08 & -0.01 & -0.01 & -0.01 & 0.01 \\
\hline 6 & 0.84 & -0.09 & -0.02 & -0.03 & -0.01 & -0.04 & -0.03 & 0.01 \\
\hline 7 & 0.79 & -0.08 & -0.06 & -0.03 & 0.04 & -0.04 & -0.01 & 0.02 \\
\hline 8 & 0.50 & 0.09 & -0.11 & 0.01 & 0.01 & 0.34 & -0.01 & 0.14 \\
\hline 9 & 0.49 & 0.11 & 0.01 & -0.16 & 0.15 & 0.05 & -0.03 & 0.12 \\
\hline 10 & 0.08 & 0.71 & -0.01 & 0.03 & -0.05 & -0.30 & 0.076 & 0.02 \\
\hline 11 & -0.02 & 0.78 & 0.03 & 0.03 & 0.05 & -0.15 & 0.05 & -0.03 \\
\hline 12 & -0.06 & 0.82 & 0.03 & -0.07 & 0.09 & 0.11 & -0.02 & 0.08 \\
\hline 13 & 0.08 & 0.76 & -0.00 & -0.03 & 0.07 & 0.08 & -0.03 & 0.09 \\
\hline 14 & -0.05 & -0.00 & 0.49 & 0.23 & 0.01 & 0.11 & 0.01 & 0.04 \\
\hline 15 & -0.08 & 0.03 & 0.81 & 0.06 & 0.04 & -0.06 & -0.04 & -0.05 \\
\hline 16 & -0.14 & -0.03 & 0.79 & -0.07 & -0.06 & 0.12 & 0.01 & 0.09 \\
\hline 17 & 0.09 & 0.09 & 0.74 & -0.05 & -0.10 & -0.16 & 0.04 & -0.05 \\
\hline 18 & 0.23 & -0.04 & 0.54 & 0.08 & 0.09 & 0.10 & -0.03 & -0.09 \\
\hline 19 & 0.05 & 0.03 & 0.05 & 0.50 & 0.19 & 0.06 & -0.03 & 0.09 \\
\hline 20 & -0.06 & 0.05 & -0.06 & 0.84 & 0.05 & -0.17 & 0.02 & -0.01 \\
\hline 21 & 0.05 & -0.06 & 0.03 & 0.72 & -0.01 & 0.02 & 0.03 & -0.00 \\
\hline 22 & -0.09 & 0.04 & 0.01 & 0.73 & -0.08 & -0.08 & 0.06 & 0.14 \\
\hline 23 & 0.12 & -0.15 & 0.11 & 0.50 & 0.16 & 0.02 & -0.03 & 0.15 \\
\hline 24 & 0.33 & -0.08 & 0.02 & -0.08 & 0.42 & -0.23 & 0.07 & 0.14 \\
\hline 25 & 0.17 & -0.09 & 0.05 & -0.05 & .50 & -.13 & .08 & .23 \\
\hline 26 & 0.03 & 0.09 & -0.01 & 0.06 & 0.92 & 0.18 & -0.02 & -0.15 \\
\hline 27 & 0.09 & 0.07 & -0.05 & 0.11 & 0.92 & 0.09 & -0.02 & -0.17 \\
\hline 28 & -0.04 & 0.06 & -0.01 & 0.04 & 0.52 & 0.14 & -0.08 & -0.19 \\
\hline 29 & 0.02 & -0.07 & 0.07 & -0.18 & 0.14 & 0.61 & 0.10 & 0.18 \\
\hline 30 & 0.06 & -0.10 & -0.02 & 0.02 & 0.05 & 0.61 & 0.12 & 0.08 \\
\hline 31 & 0.11 & 0.04 & 0.02 & 0.04 & 0.14 & 0.51 & -0.02 & 0.19 \\
\hline 32 & -0.02 & 0.06 & -0.05 & 0.06 & -0.05 & 0.09 & 0.74 & -0.04 \\
\hline 33 & 0.02 & -0.01 & 0.04 & 0.00 & -0.02 & 0.16 & 0.65 & -9.07 \\
\hline 34 & -0.14 & 0.07 & -0.02 & 0.15 & -0.28 & 0.36 & -0.01 & 0.63 \\
\hline 35 & 0.19 & 0.13 & -0.01 & 0.16 & -0.13 & 0.11 & -0.11 & 0.49 \\
\hline Eigen & 7.81 & 6.08 & 2.76 & 1.46 & 1.39 & 1.17 & 1.09 & 1.00 \\
\hline Var & 22.33 & 17.38 & 7.88 & 4.16 & 3.98 & 3.34 & 3.12 & 2.86 \\
\hline A & 0.909 & 0.869 & 0.830 & 0.799 & 0.756 & 0.616 & 0.710 & 0.395 \\
\hline
\end{tabular}

Note: Quality = Education Quality, Medium = Medium of Instruction, Info = Information about Universities, Finance = Financial Consideration, Development $=$ Chance for Self-development, Job $=$ Future Job Consideration, Family $=$ Family Consideration, Country $=$ Country Image, Eigen $=$ Eigen value, Var $=$ Explained variance, $\alpha=$ Cronbach's alpha coefficient.

The highest factor loading values are in bold 


\section{Demographic Background and the Choice of Country for Tertiary Education}

Binary logistic regression with the forward stepwise method was run to examine the association between demographic background (gender, ages, father's highest education, mother's highest education, any family members who study in any university, any family member who study in Taiwan) and the choice of Taiwan to continue tertiary education $(1=$ Yes, $2=$ No). As shown in Table 2, three demographic factors are found to be significantly corelated to the choice of Taiwan. The three demographic factors are these: Students who do not have any family member obtained tertiary education, students who have at least a family member studied or studying in Taiwan, and students whose father's highest level of education is equal or below secondary level, $\chi^{2}(6, N=869)=33.05, p<0.001$, Nagelkerke $r^{2}=0.06$.

Table 2. Demographic background and the choice of country to continue tertiary education

\begin{tabular}{lcccccc}
\hline & B & S. E. & Wald & df & Sig. & Exp(B) \\
\hline Gender (1 = Male, 2 = Female) & 0.12 & 0.16 & 0.51 & 1 & 0.48 & 1.12 \\
Ages & -0.23 & 0.14 & 2.97 & 1 & 0.09 & 0.79 \\
$\begin{array}{l}\text { Having a family member to study at university } \\
(1=\text { Yes, 2 = No) }\end{array}$ & -0.40 & 1.17 & 5.49 & 1 & 0.02 & 0.67 \\
$\begin{array}{l}\text { Having a family member to study in Taiwan } \\
(1=\text { Yes, 2 = No) }\end{array}$ & 1.08 & 0.25 & 18.09 & 1 & $<0.001$ & 2.94 \\
$\begin{array}{l}\text { Father's highest education } \\
(1=\text { Secondary or below, 2 = Above secondary) }\end{array}$ & 0.58 & 0.26 & 4.87 & 1 & 0.03 & 1.79 \\
$\begin{array}{l}\text { Mother's highest education } \\
(1=\text { Secondary or below, 2 = Above secondary) }\end{array}$ & 0.02 & 0.26 & 0.00 & 1 & 0.95 & 1.02 \\
\hline
\end{tabular}

\section{Factors Affecting Students Making Taiwan Their Choice}

A binary logistic regression was then run to examine the significance of the eight factors that led to choosing or not choosing Taiwan $(1=$ Taiwan, $2=$ others $)$. The three significant demographic background variables were used as control variables. The results showed that respondents who acknowledged the importance of medium of instruction in the universities and parents' financial consideration would choose Taiwan than other countries. However, those who perceived the importance of family issues and future job prospect were more likely to choose other countries to continue their tertiary education (see Table 3). 
Table 3. Binary regression of the eight factors for choosing or not choosing Taiwan (1 = Taiwan, 2 = others)

\begin{tabular}{lrrrrrr}
\hline & B & S.E. & Wald & df & Sig. & Exp(B) \\
\hline $\begin{array}{l}\text { Fathers' highest education } \\
\text { (1= Secondary or below, 2 = Above secondary) }\end{array}$ & 0.35 & 0.35 & 1.02 & 1 & 0.31 & 1.42 \\
$\begin{array}{l}\text { Have a family member to study at university } \\
(1=\text { Yes, 2 = No) }\end{array}$ & 1.14 & 0.38 & 9.06 & 1 & $\mathbf{0 . 0 0}$ & 3.13 \\
Have a family member to study at Taiwan & & & & & & \\
$(1=$ Yes, 2 = No) & 0.07 & 0.16 & 0.21 & 1 & 0.65 & 1.08 \\
Education quality & & & & & & \\
Medium of instruction & -0.35 & 0.26 & 1.76 & 1 & 0.19 & 0.71 \\
Information about universities & -1.58 & 0.17 & 83.98 & 1 & $<\mathbf{0 . 0 0 1}$ & 0.21 \\
Financial consideration & -0.26 & 0.19 & 1.81 & 1 & 0.18 & 0.77 \\
Chance for self-development & -0.51 & 0.18 & 7.54 & 1 & $\mathbf{0 . 0 1}$ & 0.61 \\
Future job consideration & -0.05 & 0.21 & 0.05 & 1 & 0.82 & 0.95 \\
Family consideration & 1.63 & 0.189 & 74.09 & 1 & $<\mathbf{0 . 0 0 1}$ & 5.09 \\
Country image & 0.29 & 0.10 & 9.05 & 1 & $\mathbf{0 . 0 1}$ & 1.33 \\
& -0.31 & 0.17 & 3.49 & 1 & 0.06 & 0.73 \\
\hline
\end{tabular}

\section{DISCUSSION}

Students' choice of studying in local universities after the liberation of private education in Malaysia have been extensively investigated. However, the hiking number of CIS students choosing to continue their tertiary education in Taiwan is not commonly scrutinised by Malaysian researchers. In light of this, the study aims to explore the push and pull factors affecting the choice of tertiary education to Taiwan among CIS students. As there was no appropriate measurement of tertiary education choice for CIS students in the past research, a mixed-method design was used. At the first phase of the study, a focus group discussion was conducted in order to identify the push and pull factors for developing the tool of measurement in the later phase of study. A questionnaire was subsequently designed from the discussion. After the tool or the questionnaire had been examined, the research eventually came to the second phase of study, running a survey to reach out more than a thousand of CIS students. The survey aimed to examine the correlation between demographic factors and push-pull factors to the choice of studying in Taiwan. 


\section{Push and Pull Factors}

By employing thematic analysis, the findings from the focus group discussion managed to identify eight factors. The pull factors include the quality of education, the medium of instruction in the university, the accessibility of information about the university, family consideration, country image and future job consideration. On the other hand, the push factors comprised of financial consideration and chance for self-development. It can be seen that six out of these identified factors are relevant to the pull factors rather than the push factors.

Our review of literatures has identified some common factors pushing students to study overseas. These factors encompass lack of local institutions in the higher level of education; worsening political and social situations in their home countries and better chances for self-development. In addition, loss of confidence to get a better future after graduation, lack of career opportunities, and poor financial status after graduation (Bhorat et al., 2002; Dzvimbo, 2003) were also contributed to the push factors. When applying to the current study, only two push factors emerged in our results. The first push factor is the motivation to improve self-development. This push factor indicating the situation of CIS students nowadays is different from those before the liberation of private education in Malaysia. In the past, students were pushed to study overseas because fewer opportunities were offered locally by the public universities. In addition, the second push factor or the financial consideration has suggested that CIS students face problems of high tuition fees in local private universities. Those CIS students who could not afford higher tuition fees would choose to study in Taiwan where the tuition fees are relatively lower. Furthermore, they could have more chances to get part-time jobs with better pay in order to support their living cost staying abroad.

The literature review in the present study also disclosed several distinctive pull factors in students' country choice of tertiary education. These factors complies of the country image, high-quality education, opportunity to develop excellent English language skills, choosing an experience to live in a multicultural and diverse city, the availability to gain work experience while studying, and opportunities of permanent residency (MacGregor, 2014). All of these factors have been surfacing in our study, except for the factor of family consideration. The influence of family in country choice seems to be a significant factor among Chinse students (Lee, 2017). Lee and Morrish (2012) also suggested that cultural influence should be considered a factor influencing Chinese students as their choices of studying abroad are significantly concerned by their parents. 
These results evident the view that demographic and racial differences in the country choice of tertiary education should be treated seriously (Hemsley-Brown $\&$ Oplatka, 2014). Thus, it is necessary to design a measurement tool encompassing these push-pull factors so that we would understand whether the findings could be generalised to the population of CIS students. In addition, the tool of measurement also triangulates the relationships among these factors with the choice of Taiwan as a destination of tertiary education for CIS students.

By engaging the developed scale, we surveyed 869 Senior Three students from eight CIS in different regions of West Malaysia. The results concluded these: (a) students who do not have any family member studying in any university, (b) students who have a family member studying in Taiwan, and (c) students whose father's highest education equal to or below secondary school, incline to choose Taiwan as the ultimate choice for pursuing tertiary education.

The background profile as mention implied significant emphasis of traditional Confucian cultural values in the importance of education and family which Chinese families uphold since decades. As shown in the study of Lee and Morrish (2012), both the Chinese parents and students believe that education is a way to gain success, and thus education should be the priority against all odds. In this study, even though the family members of these students possess lower education levels, they still insisted of pushing their children to continue tertiary education in an unfavourable reality such as government policies and they even prefer their children to choose Taiwan as a destination for pursuing tertiary education. This might be due to a more affordable tuition fees in Taiwan, or because of the influences of a family member's past experience studying in Taiwan.

\section{Significant Push-Pull Factors and Country Choice}

Besides demographic factors, the results of binary regression analysis showed that not all the eight push-pull factors are significantly associated with the choice of Taiwan as a destination to continue tertiary education. Among the eight factors, only pull factors are found to be significant: The medium of instruction in teaching, financial consideration, future job consideration and family consideration. To sum up, CIS students who perceived the importance of using Chinese language as a medium of instruction, those who put a weightage of financial affordability and take less importance of future job consideration or family consideration, would more likely to choose Taiwan. 
It is not surprising to count in the influence of medium of instruction as a significant predictor for the choice of Taiwan as Chinese language is the medium of teaching in CIS. The finding also evidents the importance of cultural familiarity in the country choice of tertiary education. Similarly, religion is one of the pull factors that causes Middle Eastern students to choose Malaysia as an ideal destination to continue their higher level of education (Nachatar Singh, Schapper \& Jack, 2014).

Financial consideration is another important factor associated with the choice of Taiwan for furthering tertiary education among these students. Even though tuition fees in Taiwan spikes due to the devaluation of Malaysian ringgit, the expenditure of studying in Taiwan is comparatively lower than that in Australia and Singapore. Furthermore, from a certain perspective, studying in Taiwan is even cheaper than most private universities in Malaysia. Moreover, students who choose to study in Taiwan are granted with opportunities to work part-time and getting higher wages than those in Malaysia.

Future job consideration is an essential measurement for CIS students opting the choice of Taiwan. CIS students who have decided to work in Malaysia in their future career plan are not likely to choose Taiwan as a destination of continuing their tertiary education. As a developing country, Malaysian always look for greener pastures overseas and it is estimated about one million Malaysian finding fortune abroad, especially in the countries like Singapore, the United States, Australia, and so forth (Yuan, 2017). Rare chances to use and speak English and Malay languages in Taiwan would be crucial obstacles for these CIS students who prefer to stay in Malaysia or go overseas for getting better job offers in their career path after the graduation.

Besides, comparing the distance of studying in the home country and studying abroad, either the choice making is opted by themselves or required by their family or parents, CIS students who prefer more contact hours with families or parents are also less possible to choose Taiwan as their destination of tertiary education. These CIS students would go for studying in local universities for more family bonding time.

On the whole, the findings indicate that CIS students who incline to continue their tertiary education in Taiwan are pulled by the medium of instruction in learning and financial consideration. Future job opportunity and family concern will potentially push them away from choosing Taiwan to continue their tertiary education. 


\section{CONCLUSION AND IMPLICATION}

In conclusion, the findings of this study imply that it is important to include cultural and social context while probing students' country choice of pursuing tertiary education. As mentioned by Hemsley and Oplatka (2014), it is quite impossible to jot a single list of factors describing students' choice of university as the market of tertiary education is comparatively segmented. Therefore, in terms of theoretical development, it is important to conduct more studies in order to understand specific factors causing students in a particular country. In addition, the demographic background of the respondents choosing to study in other countries is also worth scrutinised. For example, the demographic background and push-pull factors could be different for Malaysian CIS students choosing to study in Taiwan and those opting Singapore or other Western countries. In terms of practical application, policymakers and educators in Taiwan and Malaysia might need to design strategies that would pull more but push less CIS students to choose tertiary education in their countries, especially when universities are competing in this segmented market.

It should be noted that these findings also signify that even though the private tertiary education in Malaysia has been liberalised, high tuition fee has been exploiting the opportunity of higher education for students from an underprivileged background. Therefore, we expect an uprising trend of CIS students continueing their tertiary education in Taiwan. Especially for those CIS students who could not afford enrolling themselves to private universities with higher tuition fees and were politically rejected by public universities which provide cheaper tuition fees for tertiary education.

\section{LIMITATION AND SUGGESTION}

The results of factor analysis for the present study have proven the practicality of the scale we developed. To our knowledge, this is the first measurement tool that helps researchers and educators to identify factors influencing CIS students' choice of tertiary education. Nevertheless, more studies are warranted to examine the psychometric qualities of the scale further. For instance, researchers are encouraged to examine measurement invariance between genders, and also to affirm the factor structure of the 35 items by using confirmatory factor analysis. In addition, the findings of this study might not be able to generalise to all CIS students, especially those in East Malaysia, and future studies should include these students in exploring factors affecting their country choice. 


\section{ACKNOWLEDGEMENTS}

This study is sponsored by Chiang Ching-Kuo Foundation for International Scholarly Exchange (RG004-N-15).

\section{REFERENCES}

Ahmad, A. B., \& Shah, M. (2018). International students' choice to study in China: An exploratory study. Tertiary Education and Management, 24(4), 325-337. https://doi.org/10.1080/13583883.2018.1458247

Ahmad, S. Z., Buchanan, F. R., \& Ahmad, N. (2016). Examination of students' selection criteria for international education. International Journal of Educational Management, 30(6), 1088-1130. https://doi.org/10.1108/IJEM-11-2014-0145

Baldwin, G., \& James, R. (2000). The market in Australian higher education and the concept of student as informed consumer. Journal of Higher Education Policy and Management, 22(2), 139-148. https://doi.org/10.1080/713678146

Bhorat, H., Meyer, J.-B., \& Mlatsheni, C. (2002). Skilled labour migration from developing countries: Study on South and Southern Africa. Retrieved from http://ilo.org/wcmsp5/groups/public/---ed_protect/---protrav/---migrant/ documents/publication/wcms_201781.pdf

Binsardi, A., \& Ekwulugo, F. (2003). International marketing of British education: Research on the students' perception and the UK market penetration. Marketing Intelligence \& Planning, 21(5), 318-327. https://doi.org/10.1108/ 02634500310490265

Braun, V., \& Clarke, V. (2006). Using thematic analysis in psychology. Qualitative Research in Psychology, 3(2), 77-101. https://doi.org/10.1191/1478088706 qp063oa

Brown, G. K. (2007). Making ethnic citizens: The politics and practice of education in Malaysia. International Journal of Educational Development, 27(3), 318-330. https://doi.org/10.1016/j.ijedudev.2006.12.002

Chin, J. (2001). Malaysian Chinese politics in the 21st century: Fear, service and marginalisation. Asian Journal of Political Science, 9(2), 78-94. https://doi.org/ $10.1080 / 02185370108434192$

Department of Statistics Malaysia. (2018). Current population estimates, Malaysia, 2017-2018. Retrieved from https://www.dosm.gov.my/v1/index.php?r=column/ pdfPrev\&id $=\mathrm{c} 1 \mathrm{pqTnFjb29HSnNYNUpiTmNWZHArdz09}$

Dzvimbo, K. P. (2003). The international migration of skilled human capital from developing countries. Retrieved from http:/www.geocities.ws/iaclaca/ PushAndPullFactorsWorldBankReport.pdf

Hemsley-Brown, J., \& Oplatka, I. (2014). University choice: What do we know, what don't we know and what do we still need to find out? International Journal of Educational Management, 29(3), 254-274. https://doi.org/10.1108/IJEM-10 -2013-0150 
Ho, W. F. (2015, 15 November). Value of UEC beyond recognition. The Star Online. https://www.thestar.com.my/news/nation/2015/11/15/certificate-recognised -around-the-world-but-not-in-malaysia

ICEF Monitor. (2015, 5 November). The state of international student mobility in 2015. ICEF Monitor - Market Intelligence for International Student Recruitment. Retrieved from https://monitor.icef.com/2015/11/the-state-of-international -student-mobility-in-2015/

Jon, J.-E., Lee, J. J., \& Byun, K. (2014). The emergence of a regional hub: Comparing international student choices and experiences in South Korea. Higher Education, 67(5), 691-710. https://doi.org/10.1007/s10734-013-9674-0

Jongbloed, B. (2003). Marketisation in higher education, Clark's triangle and the essential ingredients of markets. Higher Education Quarterly, 57(2), 110-135. https://doi.org/10.1111/1468-2273.00238

Kamal, N., Sweeney, J. C., Soutar, G. N., \& Roberts, B. (2016). International students' university preferences: How different are Malaysian and Chinese students? International Journal of Educational Management, 30(2). http://www .emeraldinsight.com/doi/abs/10.1108/IJEM-08-2014-0122

Krueger, R. A., \& Casey, M. A. (2014). Participants in a focus group. In Focus groups: A practical guide for applied research (5th ed., pp. 63-83). SAGE. https://us.sagepub.com/en-us/nam/focus-groups/book243860

Lee, C. F. (2014). An investigation of factors determining the study abroad destination choice: A case study of Taiwan. Journal of Studies in International Education, 18(4), 362-381. https://doi.org/10.1177/1028315313497061

Lee, C. K. C., \& Morrish, S. C. (2012). Cultural values and higher education choices: Chinese families. Australasian Marketing Journal (AMJ), 20(1), 59-64. https://doi.org/10.1016/j.ausmj.2011.10.015

Lee, S. W. (2017). Circulating East to East: Understanding the push-pull factors of Chinese students studying in Korea. Journal of Studies in International Education, 21(2), 170-190. https://doi.org/10.1177/1028315317697540

MacGregor, K. (2014, 21 June). The massification of higher education in South Africa. University World News. http://www.universityworldnews.com/article.php?story $=2014062015083621$

Malaysian Qualification Agency. (2020). List of private higher education qualifications. Retrieved from https:/www2.mqa.gov.my/mqr/english/ eakrbyipts.cfm?StartRow=59

Maringe, F., \& Carter, S. (2007). International students' motivations for studying in UK HE: Insights into the choice and decision making of African students. International Journal of Educational Management, 21(6), 459-475. https://doi.org/10.1108/09513540710780000

Mazzarol, T., \& Norman Soutar, G. (1999). Sustainable competitive advantage for educational institutions: A suggested model. International Journal of Educational Management, 13(6), 287-300. https://doi.org/10.1108/09513549910294496

McLafferty, I. (2004). Focus group interviews as a data collecting strategy. Journal of Advanced Nursing, 48(2), 187-194. https://doi.org/10.1111/j.1365-2648 .2004.03186.x 
Nachatar Singh, J. K., Schapper, J., \& Jack, G. (2014). The importance of place for international students' choice of university: A case study at a Malaysian university. Journal of Studies in International Education, 18(5), 463-474. https://doi.org/10.1177/1028315314523990

Organisation for Economic Co-operation and Development (OECD). (2019). Education at a glance 2019: OECD indicators. Paris: OECD Publishing. https://doi.org/ 10.1787/f8d7880d-en

Padlee, S. F., Kamaruddin, A. R., \& Baharun, R. (2010). International students' choice behavior for higher education at Malaysian private universities. International Journal of Marketing Studies, 2(2), 202-211. https://doi.org/10.5539/ijms. v2n2p202

Siah, P. C., Christina Ong, S. B., Tan, S. M., Sim, C. P., \& Thoo, R. Y. (2018). Factors affecting school choice: What do Malaysian Chinese parents want? Journal of School Choice, 12(1), 34-51. https://doi.org/10.1080/15582159.2017.1408001

Siah, P. C., Ong, S. B. C., Tan, S. M., \& Sim, C. P. (2015). Perception on Chinese values: A comparison of Chinese secondary students studying at national secondary schools and Chinese independent schools in Malaysia. The Social Science Journal, 52(1), 62-68. https://doi.org/10.1016/j.soscij.2014.08.006

The Secretary of State for Education and Skills. (2003). The future of higher education. Retrieved from http://www.educationengland.org.uk/documents/pdfs/2003white-paper-higher-ed.pdf

The Sun Daily. (2016, 30 March). UEC not recognised due to 'national sovereignty' issue: Kamalanathan. Retrieved from https://www.thesundaily.my/archive/1743007BSARCH357753

United Chinese School Committees' Association of Malaysia. (2017). 2017 basic information of Chinese Independent School. Retrieved from https://www. dongzong.my/student/index.php/progression/uec-progression/175-2016-uec

Wong, L. P. (2008). Focus group discussion: A tool for health and medical research. Singapore Medical Journal, 49(3), 256-260; quiz 261.

Yeoh, E. K. K. (2013). Socioeconomic development and ethno-cultural diversity: State policy and the evolvement of pluralism in Malaysia. International Journal of Business Anthropology, 4(1), 121-144.

Yuan, M. (2017, 22 January). Finding fortunes in foreign lands. The Star Online. https://www.thestar.com.my/news/nation/2017/01/22/finding-fortunes-in -foreign-lands/ 